\title{
Successful Endoscopic Retrieval of a Retained Fractured Guidewire from the Main Pancreatic Duct
}

\author{
Sho Kitagawa \\ Department of Gastroenterology, Sapporo Kosei General Hospital, Sapporo, Japan
}

\section{Keywords}

Guidewire fracture · Endoscopic intervention - Endoscopic retrograde pancreatography

\section{Recuperação endoscópica bem sucedida de um fio-guia fraturado retido no ducto pancreático}

\section{Palavras Chave}

Fractura do fio-guia · Intervenção endoscópica ·

Pancreatografia retrógrada endoscópica

Guidewire fracture during endoscopic retrograde cholangiopancreatography is an uncommon event. Very few cases of fractured guidewire within the pancreatic duct have been described in the literature, and the majority of fractured guidewires appears to be irretrievable endoscopically [1]. Herein, we describe endoscopic retrieval of a retained fractured guidewire from the main pancreatic duct.

A 66-year-old man with chronic pancreatitis was referred for recurrent pancreatitis. He underwent endoscopic retrograde pancreatography to place a pancreatic plastic stent, and the pancreatogram showed 3 tight strictures at the pancreatic head (Fig. 1). When we were advancing a 0.025 -inch guidewire through the strictures, the guidewire suddenly became unresponsive, and the distal part of the guidewire was retained within the pan-

karger@karger.com www.karger.com/pjg

Karger"
(C) 2021 Sociedade Portuguesa de Gastrenterologia. Published by S. Karger AG, Basel

This is an Open Access article licensed under the Creative Commons Attribution-NonCommercial-4.0 International License (CC BY-NC) (http://www.karger.com/Services/OpenAccessLicense), applicable to the online version of the article only. Usage and distribution for commercial purposes requires written permission. creatic duct (Fig. 2). An endoscopic retrieval of the retained guidewire fragment was thus attempted.

First, we barely managed to place a 0.025 -inch guidewire (VisiGlide 2; Olympus Medical Systems, Tokyo, Japan) across the retained guidewire fragment. Next, mechanical dilatation using a long-tapered catheter (PRV220Q; Olympus Medical Systems) was performed. Then, endoscopic pancreatic sphincterotomy was performed to facilitate a smooth insertion of a biopsy forceps. Finally, the retained guidewire fragment was grasped with a biopsy forceps with a diameter of $1.8 \mathrm{~mm}$ (Cospa; Century Medical, Tokyo, Japan) and successfully retrieved under fluoroscopic guidance (Fig. 3; online suppl. Video 1, see www.karger.com/doi/10.1159/000516948). Since it took so long to perform the endoscopic retrieval, we decided to do the rest of the treatment on another day. Five days later, we successfully placed a $5-\mathrm{Fr}, 5-\mathrm{cm}$ pancreatic stent (Geenen Pancreatic Stent; Cook Medical Japan, Tokyo, Japan) by using the same devices (VisiGlide 2 and PR-V220Q) as initial treatment, and the patient was discharged 3 days after the pancreatic stent placement.

To date, there have been few reports that describe successful endoscopic retrieval of a retained fractured guidewire in the pancreatic duct with a Dormia basket $[2,3]$. However, in the current case, the main pancreatic duct was too small in diameter to use a basket catheter. To our knowledge, this is the first report of successful endoscopic retrieval of a retained fractured guidewire from the main pancre-
Correspondence to:

Sho Kitagawa, bossa0405@yahoo.co.jp 
1

Fig. 1. Pancreatogram showing tight strictures at the pancreatic head (arrows) in a 66-year-old man who presented with recurrent pancreatitis.

Fig. 2. Fluoroscopic image showing a retained fractured guidewire fragment within the main pancreatic duct.

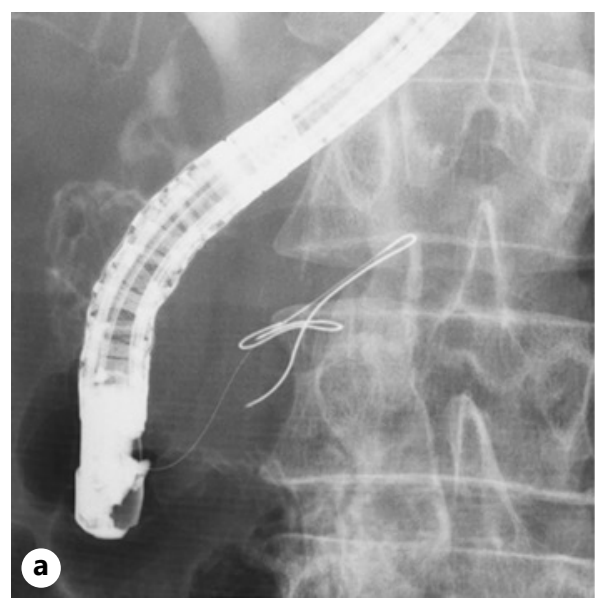

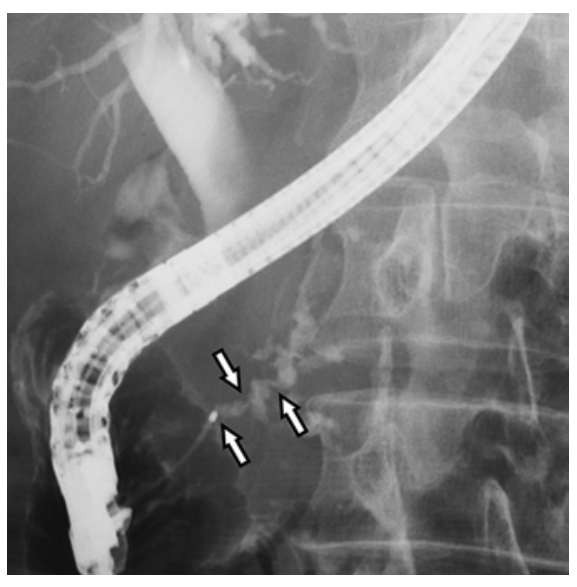

2
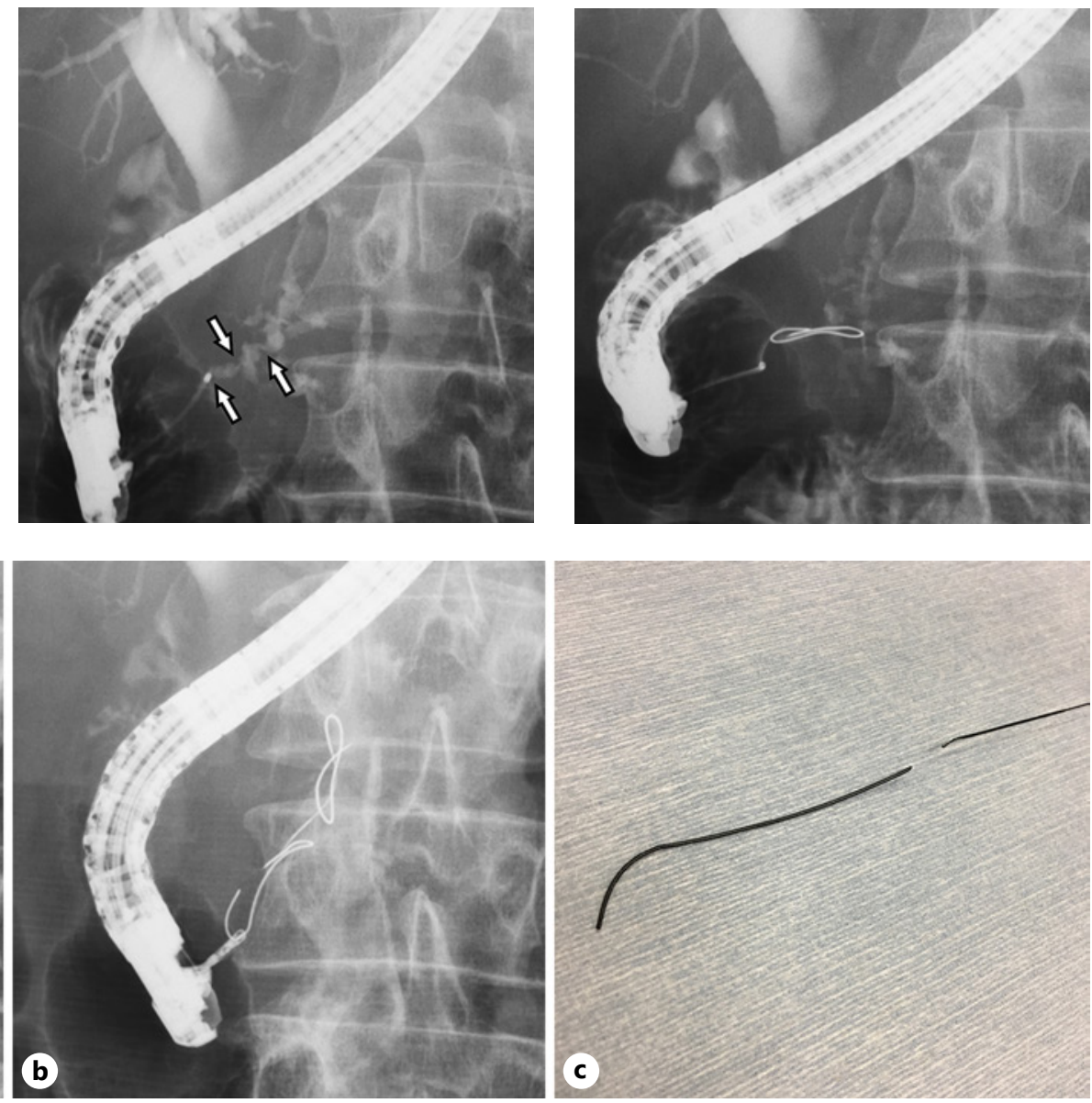

Fig. 3. a Fluoroscopic image showing a guidewire placed across the retained guidewire fragment. b Fluoroscopic image showing the retained guidewire fragment grasped with a biopsy forceps. c A $5-\mathrm{cm}$ fractured guidewire fragment retrieved from the pancreatic duct.

atic duct using a biopsy forceps. This case may help with the management of retained guidewire in the pancreatic duct even though the diameter of the pancreatic duct is small.

\section{Statement of Ethics}

Patient consent has been obtained for the publication of this report, including images.

\section{Conflict of Interest Statement}

The authors have no conflicts of interest to declare.

\section{Funding Sources}

There has been no financial support for this work.

\section{Author Contributions}

S.K. is the article guarantor and wrote the manuscript.

References Lang KA. Fractured hydrophilic guidewire during ERCP: a case series. Gastrointest Endosc. 1998 Jul;48(1):77-80.

2 Heinerman M, Mann R, Boeckl O. An unusual complication in attempted non-surgical treatment of pancreatic bile duct stones. Endoscopy. 1993 Mar;25(3):248-50.

3 Bai Y, Wang SL, Fang J, Ma D, Li ZS. Extracorporeal shock wave lithotripsy and ERCP to remove a fractured guidewire in the pancreatic duct in a patient with chronic pancreatitis and pancreatic duct stones. Gastrointest Endosc. 2016 Nov;84(5):857-8. 